\title{
Women in Iran: The effect of marital status and the presence of family dependents at home on their use of the internet
}

\author{
Yeslam Al-Saggaf
}

\author{
Saeed Shariati
}

Mark Morrison
School of Computing and Mathematics, Charles Sturt University, Australia

Corresponding Author.

yalsaggaf@csu.edu.au

School of Engineering \& Information Technology, Murdoch University, Australia

s.shariati@murdoch.edu.au

School of Management and Marketing, Charles Sturt University, Australia

mmorrison@csu.edu.au

Few studies have analyzed how women in Iranian communities use the internet. Our study investigates the effect of marital status and the presence of family dependents at home on their extent of internet use. Our analysis found that while higher incomes, having internet at home, being a student, and having higher qualifications can all increase Iranian women's chances of using the internet more regularly, looking after a husband or having family dependants at home can have a significant and negative effect on their ability to use the internet on a regular basis. The findings from our small study suggest that less time to access the internet may mean less opportunities for Iranian women to contribute to their communities such as by voicing their opinions and concerns about societal issues that matter to them and by petitioning for change. It may mean less opportunities for participating in political events such as elections.

\footnotetext{
Al-Saggaf, Y., Shariati, S., Morrison, M. (2017). Women in Iran: The effect of marital status and the presence of family dependents at home on their use of the internet. The Journal of Community Informatics, 13(3), 20-35.
}

Date submitted: 2015-08-07. Date accepted: 2017-12-13.

Copyright (C), 2017 (the author as stated). Licensed under the Creative Commons AttributionNonCommercial-ShareAlike 2.5. Available at: www.ci-journal.net/index.php/ciej/article/view/1255 
Keywords: Frequency of internet use, Iran, role of women, societal factors, inequality, regression analysis.

\section{Introduction}

While the literature is rich with accounts that focus on households' use of, and access to, the internet, there is a dearth of studies focusing on households' frequency of internet use (Lera-López, Billon, \& Gil, 2011). The limited literature on this topic indicates that higher income, having internet at home, being a student, and having higher qualifications significantly influences the frequency of internet use (Lera-López et al., 2011). This scarce literature, however, is predominantly western (Zia et al., 2009) and does not account for the differences between families in western communities and nonwestern communities.

In non-western communities, families are larger, often include the parents of the husband, and men and women are not as equal as men and women in western communities (Antonio \& Tuffley, 2014). In addition, women in non-western communities, such as in Iran, have traditional roles distinct from men. For example, even if they work full time, women are also expected to take care of the household chores, look after the children, and attend to the needs of the elderly persons in the house (Antonio \& Tuffley, 2014). This situation is different from the usual situation in western communities where households commonly consist of only parents and children, and men and women contribute more equally to the household.

To what extent can marital status and the presence of family dependents at home in the case of non-western communities such as in Iran also affect the frequency of women's internet use? With the exception of the study by Lera-López et al. (2011) that touched on family structure, no studies have looked specifically at the effect of family structure and the traditional role of women on the frequency of internet use especially in the context of developing countries. Lera-López et al. (2011) found that factors such as gender and family structure (specifically how many children are in the household) do influence the frequency of internet use, but not its use, and that frequency of use is negatively related to the presence of children in the household. This study from Spain did not focus on the traditional role of women.

There is therefore a need to understand the impact of family structure and the traditional role of women on the extent of using the internet in developing countries. The aim of this study is to investigate the effect of marital status and the presence of family dependents at home on the extent of using the internet, examining the case of women in Iran. Using a web-based survey $(N=311)$, we investigated the factors affecting the frequency of using the internet by women in Iran with a focus on understanding the influence of family structure and the traditional role of women in Iranian communities. Other variables relevant to access to internet in the literature i.e. qualifications and internet skills, infrastructure, location, sociodemographics and internet affordability were also considered. 


\section{Background}

\section{Family structure in Iran}

Most Iranian urban households are made up of large families (Bastani, 2007), where a closely related elderly person, such as an uncle or aunt or more commonly one or both of the grandparents, would be living with a nuclear family. In general, Iranians only leave the family home after getting married. In addition, depending on the family's financial circumstances, after marriage, the groom might bring the new bride to live with the rest of his family as an additional member or alternatively he might move into his in-laws' home.

Men and women in Iranian communities have distinct traditional roles (Javadian \& Singh, 2012). Men are expected to be the breadwinners while women are expected to be responsible for all home duties (Riahinia \& Azimi, 2008). For example, Iranian women do the cooking, cleaning and other household chores as well as raising the children, taking care of them, helping them with their homework and looking after other dependants at home (Javadian \& Singh, 2012). These traditional distinctions occur despite the fact that Iranian women are well represented at universities (Shirazi, 2012) and that the gender ratio in Iran is almost equally balanced (for every 1.01 males there is a female; UN, 2017).

Family relations and personal contacts are important in Iranian communities and society (Bastani, 2007). Socialising with friends and family, keeping in touch with relatives, and organizing parties and extended family gatherings are core to maintaining the social fabric of the society. However, it appears maintaining family relations and personal contacts is more of a job for females than for males (Koutlaki, 2010).

Iranian society appears to favour males over females (Yousefy \& Baratali, 2011), which is not uncommon in developing countries (Antonio \& Tuffley, 2014). An example of this favouritism is the law that requires women to obtain their husbands' permission prior to participating in employment of any kind (Javadian \& Singh, 2012). This is probably one of the reasons why Iran is at the bottom end (ranked 83 out of 147) of the 'Gender Development Factor' (GDF) scale (Javadian \& Singh, 2012). The above findings suggest the following predictions:

1. Married women are likely to use the internet less frequently

2. Women who have family dependants are likely to use the internet less frequently

The study will test these two predictions while taking into account other potential influencing factors such as qualifications, internet skills, infrastructure, location, sociodemographics and internet affordability.

\section{Women in Iranian communities and society}

Women in Iran are highly restricted in how they live their daily lives. For example, they are not allowed to get married without their male guardian's approval regardless of their age (HRW, 2015, 2017), cannot pass on their nationality to their foreign-born spouse or 
their children (Bajoghli, 2015), and cannot obtain a passport or go outside the country without the written permission of their husbands (HRW, 2015; USDOS, 2016). Additionally, they cannot attend certain sporting events, go out in public without wearing the hijab, or even ride a bike in public (HRW, 2015, Svirsky, 2016). Restrictions for women also exist in education and in the workplace.

\section{Education}

Female participation in education in Iran is high. There are no restrictions on female participation in primary and secondary education, and at university level, women now comprise the majority of students (Jacobs, 2016). However, some universities impose restrictions on what female students can study, and this appears to be a trend that is strengthening over time. For example, in 2012, 77 different fields of study at 36 universities did not accept female students (ISNA, 2013).

\section{Work}

Women are severely underrepresented in the Iranian workforce; currently only $15 \%$ of Iranian women work compared to $64 \%$ of men (HRW, 2017a). This is lower than the average for all women in the Middle East and North Africa at around 20\%. Low workforce participation for women appears to be due to societal expectations of women as well as discriminatory laws and practices that are in place. For example, the Iranian Civil Code states that an Iranian man can ban his wife from working if he believes that it would be "incompatible with the family interests or the dignity of himself or his wife" (Article 1117, p. 110). Additionally, it is not unlawful to discriminate in the hiring process, with advertisements often stating that a position is only open to men (HRW, 2017b).

\section{Women's movement}

With the number of restrictions that are in place for women, it should be of no surprise that the women's movement is strong in Iran. The Iranian women's movement first emerged in the early 20th century and has been fluctuating in strength ever since (with peaks occurring in times of more conservative governments; Ettehadieh, 2004; Sanasarian, 1982). The women's movement has resulted in a number of victories for Iranian women, such as the right to vote, run for parliament, and petition for divorce (Afkhami, 2004; Esfendiari, 2015; Vaezian, 2017). Since the internet was introduced in Iran in 1993, it has been used as a place for women to voice their concerns about discriminatory laws and behaviours and to petition for change (Shirazi, 2012). This is particularly true since 2005, when Mahmoud Ahmadinejad's government rose to power and imposed a number of restrictions that drove women's rights groups online (Abbasgholizadeh, 2014).

\section{Internet in Iran}

Iran, with a population of 79.1 million, has an internet penetration rate of 44 and a mobile phone penetration rate of $91.0 \%$. Internet speeds in Iran are among the slowest worldwide and the internet in Iran is also very expensive relative to speed, quality, and download capacities (Freedom House, 2016). One reason for this is that fluctuations in foreign exchange rates often result in increases in the cost of international data traffic. 
The socio-demographic profiles of internet users in Iran are likely to affect the extent of their internet use. A survey by Bastani and Fazel-Zarandi (2008) found that most internet users were from higher socio-economic families $(52 \%)$, had a higher level of education such as a bachelor degree or higher (50\%), were young with a mean age of 24 , were single $(69 \%)$ and were born in cities. This is consistent with a 2008 survey of 80 Iranian women that found $50 \%$ of internet users were students and the younger the users were, the more frequently they used the internet (Riahinia \& Azimi, 2008). Riahinia and Azimi's (2008) study also found that while $40 \%$ of the women used the internet between one to five hours a week, only 9\% spent between 15 to 20 hours a week on the internet. On average, the women's internet use was two hours a week, lower than the median weekly duration of internet usage by users surveyed worldwide which is 18 hours per week (Kaspersky Lab, 2015).

The Iranian government employs strict filtering of internet content. Major social networking sites like Facebook, YouTube and Twitter are not freely available in the country. When citizens began using virtual private networks (VPNs), proxies and other circumvention tools in 2009, the government authorities blocked them (Freedom House, 2016). In the past, the government relied on Chinese and Western companies to implement filtering and blocking of websites that were un-Islamic and immoral; recently, however, Iran has developed its own domestic software products so it can rely less on other countries' products. Iran has established a centralized filtering system at the Internet Service Provider (ISP) level (OpenNet Initiative, 2009).

\section{Women and the internet in Iran}

According to Shirazi (2012), since the introduction of the internet in 1993, women in Iran have used it "not only as a means of accessing and disseminating information but also as the means of voicing their concerns about discriminatory laws and to participate in public discourse. In Iran, the internet has provided a voice to repressed and maginalized groups, particularly young people and educated women" (p. 45). According to Abbasgholizadeh (2014), this is particularly true since 2005 when Mahmoud Ahmadinejad's government came into power. The election of this government saw the suppression of civil society organizations (e.g., NGO's, community-based organizations) and the imposition of restrictions on the public sphere, independent media, and any space that allowed different social groups to connect, which resulted in the gradual shift of the Iranian women's movement from the public space to online. Websites (e,g, Change for Equality, Feminist School, and Fair Family Law), blogs, and social media seem to be particularly popular ways for Iranian women to express their views (Abbasgholizadeh, 2014; Shirazi, 2012; TechRasa \& NazarBazaar, 2017). Campaigning online is also popular (e.g., One Million Signatures, the campaign by women in Iran to collect one million signatures in support of changing discriminatory laws against women in their country, and Stealthy Freedoms of Women in Iran, the campaign by Iranian women to give women the right to choose whether to wear the hijab; Change for Equality, 2017; SBS News, 2014).

It is unknown how much time women in Iran spend on the internet. As mentioned previously, a 2008 survey of 80 Iranian women found that, on average, women used the 
internet for two hours per week; however, this was a small survey consisting of only women from an Iranian university. No other statistics known to the authors exist. The barriers people in developing countries face when accessing the internet, including women in Iran, are discussed below.

\section{Factors affecting extent of use of the internet in the context of a developing country}

Lack of digital skills can be a major barrier to using the internet (Harambam, Aupers \& Houtman, 2013; Van Dijk \& Hacker, 2003). To Van Dijk (1999, as cited in Van Dijk and Hacker, 2003) the definition of digital skills is not limited to the abilities of operating computers and network connections but also includes the abilities to search, select, process and apply information from a 'superabundance' of sources. Anaraki and Heidari (2010) agree, adding that digital literacy not only helps us search and find information but also evaluate and use this information effectively. Some individuals find it hard to use the internet so they may avoid using it because they have difficulties navigating their way through the complex online world or they lack skills in using technological tools to connect and browse the internet.

Language difficulties are another reason why some people avoid using the internet (Antonio \& Tuffley, 2014). Individuals of non-English speaking backgrounds may find accessing the knowledge within the contents of the web quite difficult, with the content of the web being predominantly in English (Fragoso, Cogo, \& Brignol, 2011). Indeed, a study by Riahinia and Azimi (2008) found that some Iranian women find language to be a barrier to internet use.

The economic situation in a country also affects citizens' access to the internet (Antonio \& Tuffley, 2014; Rabayah, 2010; Van Dijk, 2006). Billon, Lera-Lopez, and Marco's (2010) empirical study shows that the greater the GDP of a country, the greater the amount of internet usage in the country because GDP has a significant role in digital development. Hargittai (1999) also found that the GDP of a country plays a large role in internet connectivity. Hanafizadeh, Hanafizadeh, and Saghaei (2009) found that telecommunications policy and the density of fixed phone lines are major players in the cause and solutions to the unequal access problem; they also found a significant relationship between telephone lines and digitalization.

In a similar vein, poor telecommunications infrastructure is a serious obstacle to citizens' ability to use the internet extensively. A correlation exists between internet uptake and telecommunications infrastructure: the better a nation's ICT infrastructure is, the better the spread of the internet (Billon et al., 2010). Anaraki and Heidari (2010) explain that facilitating internet use is not as simple as installing a few phone lines, because telecommunications companies need to implement major infrastructure across the country; providing access to the internet, even via a dial-up connection, could be a costly exercise in less developed regions.

Filtering the internet in the name of national security or to prevent citizens from accessing 'inappropriate' or 'harmful' material is another barrier to access (Al-Saggaf, 2007). Many non-democratic governments discourage the use of the internet by 
employing strict filtering of internet content, blocking legitimate content and denying citizens political participation by limiting the use of internet services (Shirazi, Ngwenyama, \& Morawczynski, 2010). Indeed, a large number of countries restrict access to the internet by implementing a filtering system at country level gateways to effectively stop users from accessing the outside internet (Anaraki \& Heidari, 2010). Shirazi, Ngwenyama, and Morawczynski (2010) found that people who live in democratic regions have a higher level of access to the internet and a greater usage of it, in comparison to regions and countries that filter and censor. They add that filtering of websites also creates a problem even for those who have access to the internet, as it affects some people more than others. For example, women in some Middle Eastern countries cannot access websites that advocate feminism or views regarding women's rights.

The above discussion focuses more on internet access and internet use and less on frequency of internet use. Internet access refers to the availability of internet connection at a house, an organisation or an institution and internet use is concerned with the use of the internet by individuals whether at home, in their organisations or at their institutions (Lera-López, Billon, \& Gil, 2011). These two areas are different from having the time to use the internet on a regular basis (Antonio \& Tuffley, 2014; Lera-López et al., 2011). This position is similar to Van Dijk's (2006) identification of four types of access: motivational access, material and physical access, skills access and usage access (because of lack of time). The current study focuses on the frequency of the use of the internet by individuals within their households, an area Lera-López et al. (2011) noted is seldom explored.

The limited literature indicates that higher income, having internet at home and education affect individuals' frequency of the use of the internet (Billon, Marco, \& Lera-Lopez, 2009; Hargittai, 1999). Another factor is having the time to use the internet (Antonio \& Tuffley, 2014). Van Dijk (2006) noted that unequal use of the internet is not only related to lower income, lack of computer and internet equipment, lack of technical knowledge, lack of qualifications, and lack of motivation to use the internet but also having the time to use the internet. The current study also found that higher income, having internet at home, being a student, and having higher qualifications significantly influence Iranian women's frequency of internet use.

However, with the exception of the Lera-López et al. (2011) study nothing has been found in the literature relating to the relationship between family structure and the traditional role of women in communities and the time available to use the internet in the context of a developing country. While Van Dijk (2006) identified lack of time, i.e., usage access, as an obstacle to accessing the internet, his focus was on internet access not the extent of use and he did not explore what causes this lack of time. Antonio and Tuffley (2014) commented on the relationship between women's lack of free time and the opportunity to access the internet, but their work was based on a review of the literature, not an empirical study. While Al-Saggaf (2007) blamed the Arabic culture, particularly the aspect of women's shyness and modesty, for discouraging Arab women in particular from accessing information that could be beneficial, educational, or even informing to them, Al-Saggaf's research did not explore the relationship between family 
structure and the traditional role of women and using the internet on a regular basis. The current study is significant because it seeks to address this gap in the literature. In the next sections, the study method and results are detailed.

\section{Method}

\section{Survey}

Data was collected for this study using a web-based survey. The survey method was chosen given the ease of gathering data, lower cost, quicker survey completion and convenience for the participants. Li et al. (2004) noted that internet surveys have been demonstrated to be a cost-effective method of obtaining data for population surveys.

The questionnaire focused on four main areas: access, skills, infrastructure and affordability. Access variables included the presence of dependants at home, the ownership of mobile phones and computers, the presence of internet at home and more importantly internet usage per week. Skills variables included qualifications and computer and internet skills (e.g., basic, intermediate or advanced). In addition to asking participants about their geographic location (e.g., rural or urban), the infrastructure questions focussed on the connection method (i.e., dial up or broadband) and the connection speed (e.g., $56 \mathrm{kbs}$ or over $128 \mathrm{kbs}$ ). Finally, the affordability questions focussed on participants' employment status, household income, and internet costs.

The questionnaire was administered using SurveyMonkey (www.surveymonkey.com) and was prefaced by the informed consent sheet and information about the ethics approval to conduct the study. The questionnaire was offered in Farsi, the national language of Iranians, because the majority of Iranians do not speak English fluently. At the end of the survey period, all responses received were translated from Farsi into English.

To invite respondents, the researchers placed invitations explaining the nature of the study and providing a link to it on social networking sites (SNS). To complete the survey, participants needed to be Iranian adults living in Iran who have some access to the internet and some basic computer and internet skills. It should be noted that while it is true that some SNS, such as Facebook and Twitter, are blocked in Iran, a large majority of Iranians are active on these sites because they are able to bypass the filtering mechanisms.

Three hundred and eleven female participants $(N=311)$ completed the survey. In terms of age, 35.36\% $(n=110)$ of the participants were aged between 18 and 29 years old, $43.7 \%(n=136)$ were between 30 and 50 years old and $20.9 \%(n=65)$ were above 50 years old. In terms of their marital status, $63 \%(n=197)$ were married, $20.5 \%(n=64)$ were single, $4.8 \%(n=15)$ were widows/widowers, $10.6 \%(n=33)$ were divorced and two female participants did not indicate their marital status.

\section{Statistical analysis}


To understand the influence of the different variables on internet usage, we used regression analysis. Since the questionnaire responses of interest were mostly ordered outcomes, ordinal regression techniques were used to model the data. In this study, the use of regression analysis allowed the modelling of the relationship between 'weekly internet usage' and the socio-demographic covariates. The ordered logit model is commonly specified as follows:

$$
y_{i}^{*}=\beta^{\prime} x_{i}+\varepsilon_{i}
$$

where $y_{i}$

$$
\begin{aligned}
& =0 \quad \text { if } y_{i} \leq \mu_{0} \\
& =1 \quad \text { if } \mu_{0}<y_{i} \leq \mu_{1} \\
& =2 \quad \text { if } \mu_{1}<y_{i} \leq \mu_{2} \\
& \ldots \\
& =J \quad \text { if } y_{i}>\mu_{J-1} .
\end{aligned}
$$

Figure 1: The ordered logit model

The free parameters $\mu \mu$ represent the cut-off between ranks. Further details about this model can be found in Train (2003).

A single ordered logit model has been estimated to demonstrate the influence of dependants at home, marital status, income, internet at home, employment status and qualifications on weekly internet usage. A general to specific approach was used to identify this set of significant regressors, with insignificant regressors excluded from the model.

\section{Results}

Before presenting the regression results, we will first examine how the mean values for the explanatory variables in the regression equation change across different levels of weekly internet usage. It is apparent that for all of the variables in Table 1 there is either a monotonically increasing or decreasing relationship with the number of days per week that the internet is used. The average values for the two variables of most interest in this study - the percentage of respondents having dependents and being married - both decrease with internet usage, though the largest change is between the two lowest levels of internet usage. The remaining variables (income, internet at home, student and degree) all increase with increasing internet usage, and substantively increase across all levels of weekly internet usage.

Table 1: Average socio-demographic values across weekly internet usage groups

\begin{tabular}{lccc}
\hline \multirow{2}{*}{ Variable } & \multicolumn{3}{c}{ Weekly internet usage } \\
\cline { 2 - 4 } & 1 day & $2-3$ days & $4-7$ days \\
\hline Anyone dependent on you & .90 & .69 & .65 \\
Married & .81 & .51 & .50
\end{tabular}




\begin{tabular}{llll} 
Mid income & .14 & .37 & .50 \\
High income & .01 & .07 & .16 \\
Internet at home & .67 & .79 & .93 \\
Student & .03 & .07 & .25 \\
Degree & .04 & .38 & .56 \\
\hline
\end{tabular}

Note. All values are percentages.

The regression results are presented in Table 2. The regression has a McFadden rhosquare value of 0.235 , which is equivalent to an $\mathrm{R}^{2}$ value of over $50 \%$ in standard regression analysis (McFadden, 1973). Thus, this result indicates that the model has a good fit with respect to the ability of the independent variables to explain changes in the dependent variable. Seven of the explanatory variables considered were significant. With respect to the primary aim of the study, which sought to investigate whether family structure is related to the time available to access the internet, the coefficient for the 'Anyone dependent on you' variable (-0.790) was negatively signed and significant $(p=0.013)$. The negative sign of the coefficient indicates that respondents who have family dependants at home are likely to access the internet less. Similarly, for the second variable that is related to the role of women in society - Married - the coefficient $(-.689)$ is negative and significant $(p=0.017)$. Similar to having someone dependent on you, the negative coefficient indicates that respondents who have a husband at home are likely to access the internet less.

In contrast, the coefficients for the other explanatory variables considered, i.e., high income (1.784), mid income (1.186), internet at home (0.986), being a student (1.686) and having a degree (1.478), were found to be positively related to the amount of time available to women in Iran to access the internet during the week. All coefficients are also highly significant $(p<0.01)$. These results indicate that having high or mid income, having the internet at home, being a student or having a degree increases the likelihood that women will use the internet on more days during the week.

Further insight can also be gained by comparing the magnitude of the negatively signed variables ('anyone dependent on you' and 'married') with the five positively signed variables. The magnitudes of the coefficients for the five positively signed variables (high and mid income, internet at home, student, and degree) are all larger than the negative coefficients for having adult dependents or being married. This implies that the positive effects on internet usage of higher sociodemographic status, education or improved internet access more than offset the negative effects due to family structure.

Table 2: Ordered logit regression showing the effect of various explanatory variables on weekly internet usage

\begin{tabular}{lccc}
\hline Variable & Coefficient & Standard error & P-value \\
\hline$\mu_{1}$ & .314 & .381 & .409 \\
$\mu_{2}$ & 2.242 & .409 & .000
\end{tabular}




$\begin{array}{lccc}\text { Anyone dependent on you } & -.790 & .317 & .013 \\ \text { Married } & -.689 & .290 & .017 \\ \text { Mid income } & 1.186 & .292 & .000 \\ \text { High income } & 1.784 & .615 & .004 \\ \text { Internet at home } & .986 & .327 & .003 \\ \text { Student } & 1.686 & .448 & .000 \\ \text { Degree } & 1.478 & .319 & .000\end{array}$

\section{Discussion and conclusion}

As predicted, women respondents who have family dependants or who look after a husband at home have less time to use the internet more frequently, making family structure and the traditional role of women a major obstacle to accessing the internet on a regular basis. However, family dependants and spouses are not the only factors that explain less frequent internet usage. The results of this study indicate that women who have higher incomes, internet at home, are studying, or who have higher qualifications tend to enjoy higher levels of weekly internet usage. However, having family dependants or a husband to look after at home can diminish women's opportunities to use the internet regularly. In light of this study's findings, the model in Figure 2 is proposed. We recommend that the proposed model is further tested in future studies using samples from other developing countries particularly those in the Middle East:

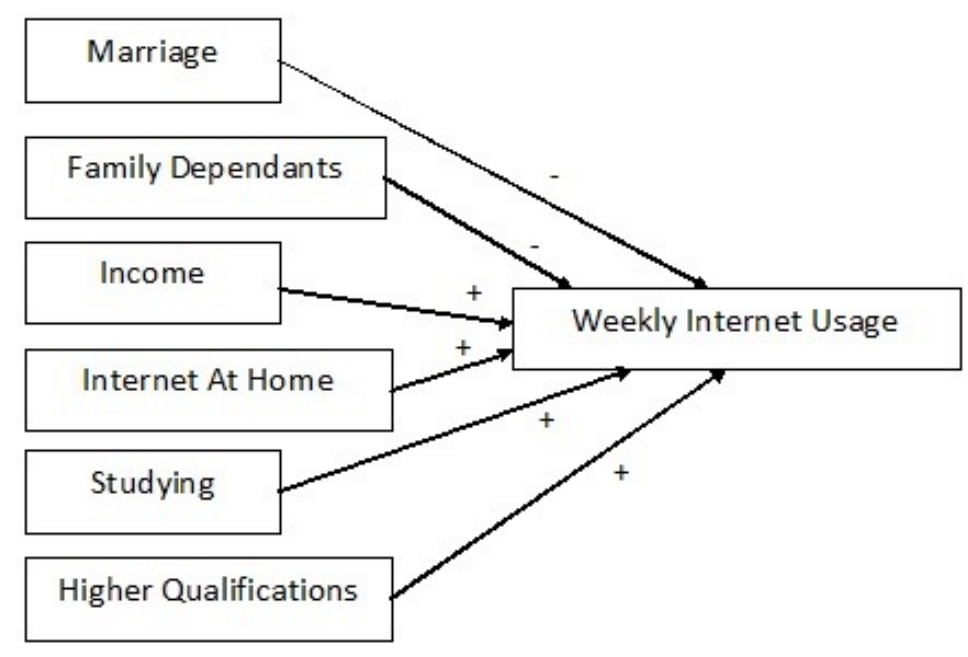

Figure 2: The proposed model

Our study investigated the factors affecting the amount of time available to women in Iran to access the internet with a focus on family structure and the traditional role of women in Iranian communities. The key finding from this study is that while higher income, having internet at home, being a student, and having higher qualifications can all increase the chances of accessing the internet more regularly, having family dependants or looking after a husband at home can be a major obstacle to accessing the 
internet on a regular basis. As predicted, family structure and the traditional role of women were found to have a significant and negative effect on women's sustained access to the internet.

This study has empirically demonstrated that the traditional role of women and family structure can play a major role in minimising the time available to women to use the internet frequently. Given the lack of prior empirical studies on this topic, this current study makes a contribution to this literature. Public opinion and policy are mainly concerned with having connectivity to the internet due to the perception that the information inequality problem can be solved when people are connected to the internet (van Dijk \& Hacker, 2003). Frequency of access is often neglected because it is assumed that it is the choice the user makes (van Dijk \& Hacker, 2003). The results of this study indicate that women in Iran who have family dependants at home to look after or whose husbands expect them to do the cooking, cleaning and other household chores in addition to raising children and caring for adult dependents, are likely to have less time to use the internet. Van Dijk (2006) argues that reduced internet usage has the potential of isolating women in society. If this happens, they may lack the means necessary for full participation in society (Van Dijk, 2006). For this reason, policies designed to help women in Iran to express themselves online (Antonio \& Tuffley, 2014) should take into account the role culture plays in reducing the time available to them to use the internet. Tavani (2011) noted that when important policies are made about the internet, women are excluded. New policies should include women in the discussion about the use of the internet and should aim to boost their participation (Tavani 2011). This is particularly important as the results of this study indicate that policies aimed at addressing sociodemographic disadvantage (e.g., via study or providing internet access at home) have the potential to more than offset the disadvantage due to marital status and family structure.

There are a number of implications for Iranian women from lack of regular access to the internet. Less time to access the internet may mean less opportunities for Iranian women to contribute to their communities such as by voicing their opinions and concerns about societal issues that matter to them and by petitioning for change. It may mean less opportunities for participating in political events such as elections.

At the individual level, women who do not have regular access to the internet may miss out on accessing a number of opportunities on a regular basis, such as shopping online and banking online; services that exist in Iran. Applying for jobs is another area that may be impacted by less frequent access to the internet. As jobs in Iran are increasingly advertised on the internet and candidates are expected to submit their applications online or send them by email rather than by post, lack of regular access to the internet may affect employment opportunities.

E-health services are abundant online. One can purchase private health insurance, find information about hospital services, seek advice, update private health records, pay bills and make appointments with general practitioners. Even in developing countries such as Iran, lack of regular access to the internet would result in less access to several health services such as the ability to search for medical centres and pharmacies nearest to 
patients, and the ability to find information about medications and medical assistance and general advice. Given women in Iran are in charge of raising the children and taking care of them, frequent access to information relating to medical services is of particular importance.

The internet has revolutionised education and online education has made it possible for many, including women, to study from home. Most universities offer their courses online with students having the option of studying either face-to-face or online or both. Courses can be fully online where students can search for a course they would like to do in their local area, enrol in it, attend lectures, download course materials, participate in class discussions, do the research for their assignments, submit their assignments to their lecturers, and complete exams. Lack of regular access to the internet may make it difficult for some students to learn online.

Three limitations to the present study and suggestions for future research are outlined. Firstly, the analysis of data focused only on women. A future study could examine the effect of marital status and the presence of family dependents at home on men's extent of using the internet. Secondly, this study collected data from a small sample of 311 women. This affects the generalisability of the findings. A future study could recruit a larger sample to address the issue of the generalisability of the findings. Thirdly, while the study explored the effect of marital status and the presence of family dependents at home on women, the study's survey did not ask the study's participants directly about this issue. A future study could consider asking potential participants this question directly in the survey to facilitate comparison of the findings from both approaches.

\section{Acknowledgments}

The authors wishes to thank Susan O'Donnell (University of New Brunswick) and Rachel MacCulloch (Charles Sturt University) for their valuable contributions to this article.

\section{References}

Abbasgholizadeh, M. (2014). "To do something we are unable to do in Iran": Cyberspace, the public sphere, and the Iranian women's movement. Signs: Journal of Women in Culture and Society, 39, 831-840.

Afkhami, M. (2004). The women's organization of Iran: Evolutionary politics and revolutionary change. In L. Beck \& G. Nashat (Eds), Women in Iran from 1800 to the Islamic Republic. Chicago, IL: University of Illinois Press.

Al-Saggaf, Y. (2007). The digital divide within the digital community in Saudi Arabia. In E. Rooksby \& J. Weckert (Eds), Information technology and social justice (pp. 262-282). Hershey, PA: IGI.

Anaraki, L. N., \& Heidari, A. (2010). Bridging the digital divide: A review of critical factors in developing countries. In T. Ashraf, J. Sharma, \& P. Gulati (Eds), Developing sustainable digital libraries: Socio-technical perspectives (pp. 286-310). Hershey, PA: Information Science Reference. 
Antonio, A., \& Tuffley, D. (2014). The gender digital divide in developing countries. Future Internet, 6(4), 673-687.

Bajoghli, N. (2015, November 9). Iran's unfair nationality laws. MER 281 Activism. Retrieved from http://www.merip.org/irans-unfair-nationality-laws

Bastani, S. (2007). Family comes first: Men's and women's personal networks in Tehran. Social Networks, 29(3), 357-374.

Bastani, S., \& Fazel-Zarandi, M. (2008). The effect of internet usage on interpersonal relationships: A case study. Proceedings of the 41st Annual International Conference on System Sciences, Hawaii, January 2008, 61-61. Hawaii: IEEE.

Bates, J. (2012). "This is what modern deregulation looks like" : Co-optation and contestation in the shaping of the UK's open government data initiative. The Journal of Community Informatics, 8(2). Retrieved from http://ci-journal.net/index.php/ciej/article/view/845.

Billon, M., Lera-Lopez, F., \& Marco, R. (2010). Differences in digitalization levels: A multivariate analysis studying the global digital divide. Review of World Economics, 146(1), 39-73.

Billon, M., Marco, R., \& Lera-Lopez, F. (2009). Disparities in ICT adoption: A multidimensional approach to study the cross-country digital divide. Telecommunications Policy, 33, 596-610.

Change for Equality. (2017). Launching of the One Million Signatures Campaign Demanding Changes to Discriminatory Laws. Retrieved from http://we-change.org/site/english/ spip.php?article20

Civil Code of the Islamic Republic of Iran (Iranian Civil Code). Retrieved from http:// www.alaviandassociates.com/documents/civilcode.pdf

Esfandiari, H. (2015). The women's movement. Retrieved from http://iranprimer.usip.org/ resource/womens-movement

Ettehadieh, M. (2004). The origins and development of the women's movement in Iran, 1906-41. In L. Beck \& G. Nashat (Eds), Women in Iran from 1800 to the Islamic Republic. Chicago, IL: University of Illinois Press.

Fragoso, S., Cogo, D., \& Brignol, L. D. (2011). What does it mean to bridge the divide?: Learning from spontaneous practices towards ICTs. In J. Steyn, \& G. Johanson (Eds.), ICTs and sustainable solutions for the digital divide: Theory and perspective (pp. 151-170). Hershey, PA: Information Science Reference.

Freedom House. (2016). Freedom on the net 2016: Iran country profile. Retrieved from https:// freedomhouse.org/report/freedom-net/2016/iran

Hanafizadeh, M. R., Hanafizadeh, P., \& Saghaei, A. (2009). The pros and cons of digital divide and e-readiness assessments. International Journal of E-Adoption (IJEA), 1(3), 1-29.

Harambam, J., Aupers, S., \& Houtman, D. (2013). The contentious gap. Information, Communication \& Society, 16, 1093-1114,

Hargittai, E. (1999). Weaving the western web-explaining differences in internet connectivity among OECD countries. Telecommunications Policy, 23, 701-718.

Human Rights Watch (HRW). (2015). Women's rights in Iran. Retrieved from https:// www.hrw.org/news/2015/10/28/womens-rights-iran

Human Rights Watch (HRW). (2017a). Iran: Women face bias in the workplace. Retrieved from https://www.hrw.org/news/2017/05/25/iran-women-face-bias-workplace 
Human Rights Watch (HRW). (2017b). "It's a men's club": Discrimination against women in Iran's job market. Retrieved from https://www.hrw.org/report/2017/05/25/its-mensclub/discrimination-against-women-irans-job-market

Iranian Students News Agency (ISNA). (2013). Women's rights defenders filed a complaint against 36 universities at the administrative justice court. Retrieved from https:// www.isna.ir

Jacobs, J. D. (2016, December 7). Educated, yet excluded: Why access to education for Iranian women is not enough. Brown Political Review. Retrieved from http:// www.brownpoliticalreview.org/2016/12/education-iranian-women/

Javadian, G., \& Singh, R. P. (2012). Examining successful Iranian women entrepreneurs: An exploratory study. Gender in Management: An International Journal, 27(3), 148-164.

Kaspersky Lab. (2015). Consumer security risks survey 2015. Retrieved from https:// www.kaspersky.com

Koutlaki, S. (2010). Among the Iranians: A guide to Iran's culture and customs. Yarmouth, ME: Nicholas Brealey Publishing.

Lera-López, F. Billon, M., \& Gil, M. (2011). Determinants of internet use in Spain. Economics of Innovation and New Technology, 20(2), 127-152,

McFadden, D. (1973). Conditional logit analysis of qualitative choice behaviour. In P. Zarembka (Ed), Frontiers in econometrics. New York, NY: Academic Press.

Morrison, M., \& Hatfield-Dodds, S. (2011). The success and failure of An Inconvenient Truth and the Stern Report in influencing Australian public support for greenhouse policy. The Economic Record, 87, 269-281.

OpenNet Initiative. (2009). Internet filtering in Iran. Retrieved from http://opennet.net/research/ profiles/iran

Rabayah, K. S. (2010). Economic and social empowerment of women through ICT: a case study of Palestine. The Journal of Community Informatics, 5(3-4). Retrieved from http://cijournal.net/index.php/ciej/article/view/500/508

Riahinia, N., \& Azimi, A. (2008). Women and the web: An evaluation of academic Iranian women's use of the internet in Tarbiat Moalem University. The Electronic Library, $26(1), 75-82$.

Sanasarian, E. (1982). The women's rights movement in Iran. New York. NY: Praeger.

SBS News. (2014, May 14). Iran women flout dress code in online campaign. Retrieved from https://www.sbs.com.au/news/iran-women-flout-dress-code-in-online-campaign

Shirazi, F. (2012). Information and communication technology and women empowerment in Iran. Telematics and Informatics, 29(1), 45-55.

Shirazi, F., Ngwenyama, O., \& Morawczynski, O. (2010). ICT expansion and the digital divide in democratic freedoms: An analysis of the impact of ICT expansion, education and ICT filtering on democracy. Telematics and Informatics, 27(1), 21-31.

Svirsky, M. (2016, September 22). Iran forbids women from riding bicycles. Clarion Project. Retrieved from https://clarionproject.org/iran-forbids-women-riding-bicycles/

TechRasa \& NazarBazaar. (2017). The state of internet and social media usage in Iran. Retrieved from http://techrasa.com/wp-content/uploads/2017/06/Internet-Social-MediaUsage-Iran-1.jpg 
Train, K. (2003). Discrete choice methods with simulation. Cambridge, UK: Cambridge University Press.

United Nations (UN). (2017). World population prospects 2017. Retrieved from https:// esa.un.org/unpd/wpp/Download/Standard/Population/

UNDOS. (2017). Country report on human rights practices 2016 - Iran. Retrieved from https:// www.ecoi.net/local_link/337185/466945_en.html

Vaezian, H. (2017). An overview of the women's movement in Iran. Analize - Journal of Gender and Feminist Studies, 8, 107-117.

Van Dijk, J. (2006). The network society: Social aspects of new media (2nd ed.). London, UK: Sage.

Van Dijk, J. \& Hacker, K. (2003). The digital divide as a complex and dynamic phenomenon. The Information Society: An International Journal, 19, 315-326.

Yousefy, A., \& Baratali, M. (2011). Women, employment and higher education schoolings. Procedia - Social and Behavioral Sciences, 15, 3861-3869.

Zia, T., Al-Saggaf, Y., Islam, M. Z., Zheng, L., \& Weckert, J. (2009). The digital divide in Asia: Cases from Yemen, Bangladesh, Pakistan and China. Journal of Information Ethics, 18(2), 50-76. 